\title{
A!
}

This is an electronic reprint of the original article.

This reprint may differ from the original in pagination and typographic detail.

Henkel, Alexander P.; Caic, Martina; Blaurock, Marah; Okan, Mehmet

\section{Robotic transformative service research}

Published in:

JOURNAL OF SERVICE MANAGEMENT

DOI:

10.1108/JOSM-05-2020-0145

Published: 15/08/2020

Document Version

Publisher's PDF, also known as Version of record

Published under the following license:

CC BY

Please cite the original version:

Henkel, A. P., Caic, M., Blaurock, M., \& Okan, M. (2020). Robotic transformative service research: Deploying social robots for consumer well-being during COVID-19 and beyond. JOURNAL OF SERVICE MANAGEMENT, 31(6), 1131-1148. https://doi.org/10.1108/JOSM-05-2020-0145

This material is protected by copyright and other intellectual property rights, and duplication or sale of all or part of any of the repository collections is not permitted, except that material may be duplicated by you for your research use or educational purposes in electronic or print form. You must obtain permission for any other use. Electronic or print copies may not be offered, whether for sale or otherwise to anyone who is not an authorised user. 


\title{
Robotic transformative service research: deploying social robots for consumer well-being during COVID-19 and beyond
}

Social robots for consumer well-being

\author{
Alexander P. Henkel \\ Department of Organization and \\ Center for Actionable Research of the Open University (CAROU), \\ Open University of the Netherlands, Heerlen, The Netherlands \\ Martina Čaić \\ Department of Design and Architecture, School of Arts, \\ Aalto University, Espoo, Finland and \\ CERS - Centre for Relationship Marketing and Service Management, \\ Hanken School of Economics, Helsinki, Finland and \\ CTF - Service Research Center, Karlstad Universitet, Karlstad, Sweden \\ Marah Blaurock \\ Department of Marketing and Management, University of Hohenheim, \\ Stuttgart, Germany, and \\ Mehmet Okan \\ Faculty of Management, Artvin Coruh University, Artvin, Turkey
}

\begin{abstract}
Purpose - Besides the direct physical health consequences, through social isolation COVID-19 affects a considerably larger share of consumers with deleterious effects for their psychological well-being. Two vulnerable consumer groups are particularly affected: older adults and children. The purpose of the underlying paper is to take a transformative research perspective on how social robots can be deployed for advancing the well-being of these vulnerable consumers and to spur robotic transformative service research (RTSR).

Design/methodology/approach - This paper follows a conceptual approach that integrates findings from various domains: service research, social robotics, social psychology and medicine.

Findings - Two key findings advanced in this paper are (1) a typology of robotic transformative service (i.e. entertainer, social enabler, mentor and friend) as a function of consumers' state of social isolation, well-being focus and robot capabilities and (2) a future research agenda for RTSR.
\end{abstract}

(C) Alexander P. Henkel, Martina Čaić, Marah Blaurock and Mehmet Okan. Published by Emerald Publishing Limited. This article is published under the Creative Commons Attribution (CC BY 4.0) license. Anyone may reproduce, distribute, translate and create derivative works of this article (for both commercial and non-commercial purposes), subject to full attribution to the original publication and authors. The full terms of this license may be seen at http://creativecommons.org/licences/by/4.0/ legalcode

This paper forms part of a special section "The Coronavirus Crisis and Beyond: Implications for Service Research and Practice", guest edited by Dr. Volker G. Kuppelwieser and Dr. Jörg Finsterwalder.

The authors want to express their gratitude to the organizers of the 2018 Let's Talk About Service (LTAS) workshop in Ghent (Belgium), and particularly Prof. Bart Larivière, for facilitating the collaboration that has led to this project. Further, the authors want to thank Niloofar Borghei Razavi for her valuable feedback on an earlier draft of this paper.

Funding: This research was supported by the Province of Limburg, The Netherlands, under grant number SAS-2019-00247 and the Foundation for Economic Development, Finland (lsr.fi).
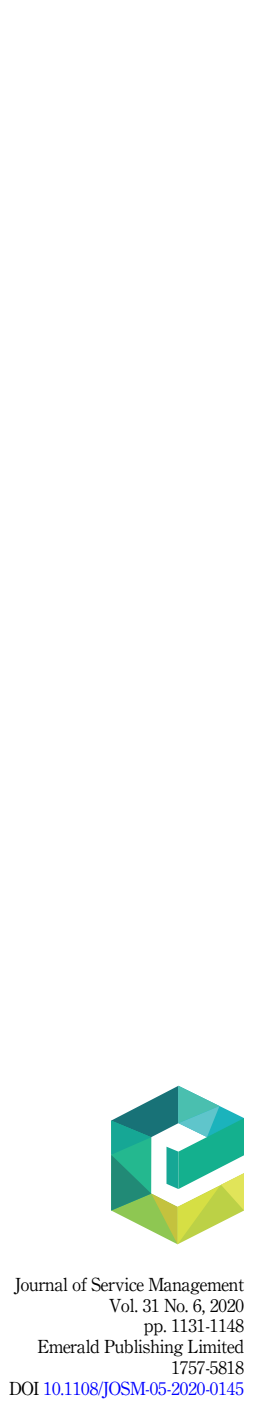
JOSM 31,6

Practical implications - This paper guides service consumers and providers and robot developers in identifying and developing the most appropriate social robot type for advancing the well-being of vulnerable consumers in social isolation.

Originality/value - This study is the first to integrate social robotics and transformative service research by developing a typology of social robots as a guiding framework for assessing the status quo of transformative robotic service on the basis of which it advances a future research agenda for RTSR. It further complements the underdeveloped body of service research with a focus on eudaimonic consumer well-being.

Keywords Social robots, Vulnerable consumers, COVID-19, Eudaimonic well-being, Robotic transformative service research

Paper type Conceptual paper

COVID-19 acts as a major disruptive factor for service consumers. The concerted world-wide quarantine measures that impose on consumers to live in social isolation have immediate and long-term detrimental psychological health consequences (Brooks et al., 2020). These negative effects are exacerbated for vulnerable consumer groups, particularly older adults and children (Holmes et al., 2020). Even with easing of the COVID-19 measures, a significant share of vulnerable consumers likely continues to live under restricted social contact and suffers from durable negative psychological health outcomes (e.g. older adults who represent a high-risk group; World Health Organization, 2020a).

A promising avenue to counter the adverse consequences of social isolation for vulnerable consumers is provided by the field of social robotics (e.g. de Graaf et al., 2015). Social robots are physically embodied agents designed for assisting and engaging in social interactions with humans in their everyday lives (Fong et al., 2003). An example is Pepper [1], a social robot that can interact with humans through conversation and its touch screen. Social robots can provide service to consumers without human interaction and may, thus, be deployed to create uplifting changes for consumer well-being during COVID-19 and beyond.

Even though the past decade of service research has witnessed the foundation and surge of how service can transform the well-being of consumers (Anderson, 2010; Anderson et al., 2013; Anderson and Ostrom, 2015; Gustafsson et al., 2015), alongside an increasing accentuation of the role of robots in service (Caić et al., 2018; Mende et al.,2019; van Doorn et al., 2017; Wirtz et al., 2018), a systematic integration of social robots and transformative service research (TSR) is still in a nascent stage. As a consequence, the question of how social robots might assist vulnerable consumers to attenuate, or even reverse the negative psychological health consequences of social isolation and advance well-being, remains unaddressed.

The underlying paper draws from the fields of social robotics (e.g. de Graaf et al., 2015), medicine (e.g. Hawkley; Cacioppo, 2010), social psychology (Ryan and Deci, 2001) and service research (e.g. Anderson et al., 2013) to derive interdisciplinary insights into how social robot service may improve vulnerable consumer well-being when facing social isolation. In doing so, it aims to contribute to service theory and practice by advancing a social robot perspective of TSR: robotic TSR (RTSR), which we define as the integration of social robot and transformative service research that focuses on well-being-relevant outcomes of consumer and employee interactions with social robots. First, this study synthesizes findings from social robotics based on a typology of robotic transformative service to derive an understanding of the status quo and future potential of transforming vulnerable consumer well-being in social isolation. Second, it extends this synthesis and identifies a future research agenda for the newly identified sub-area of RTSR.

\section{COVID-19 and social isolation}

Extended periods of social distancing and isolation can seriously deteriorate the psychological well-being of individuals (Brooks et al., 2020). The consequences of the 
worldwide measures to combat COVID-19 force consumers into a deficiency of social contact or objective social isolation (Hawkley and Cacioppo, 2010; Steptoe et al., 2013). Though few individuals may lead solitary lives without feeling lonely, generally recent evidence documents a significant predictive effect of social disconnectedness on subjective social isolation (Santini et al., 2020). The latter is equated with loneliness or the distress concerning the quality or quantity of one's social relationships.

In particular, this subjective state of social isolation is associated with severe negative implications for physical, psychological and cognitive health (Hawkley and Cacioppo, 2010). Various longitudinal studies suggest subjective social isolation as a risk factor for physical health deterioration and mortality (e.g. Cacioppo et al., 2002; Holt-Lunstad et al., 2015; Steptoe et al., 2013). Further, it is associated with increased moodiness and depression (Cacioppo et al., 2006), faster cognitive decline and an intensified sensitivity to social threats (Bassuk et al., 1999; Cacioppo and Hawkley, 2009). Subjective social isolation is most prevalent among children and older adults (Pinquart and Sorensen, 2001), making them a particularly vulnerable consumer group during COVID-19.

\section{Vulnerable consumer needs and well-being}

Consumer vulnerability can be described as "a state in which consumers are subject to harm because their access to and control over resources are restricted in ways that significantly inhibit their ability to function in the marketplace" (Hill and Sharma, 2020, p. 1). Thus, this paper focuses on those consumers who are especially prone to suffer mental health consequences during COVID-19; non-adolescent children before puberty and people of 65 years of age and older (Holmes et al., 2020), which will be simply referred to as children and older adults in the remainder of the paper (Kabadayi et al., 2020). Depending on their degree of agency and autonomy, these groups may, particularly, struggle with accessing services that can help them overcome suffering through resource losses (e.g. Henkel et al., 2017); hence, they both deserve specific attention from service research and offer ample potential for service to positively transform their well-being (Anderson et al., 2013). Accordingly, the World Health Organization (2020b) emphasized the potential repercussions of COVID-19 measures on the mental health of exactly these two vulnerable groups and advocated their guidance.

Research on well-being is broadly approached from one of two perspectives: hedonic and eudaimonic (Ryan and Deci, 2001). Hedonic well-being is equated with pleasure and happiness and often operationalized as satisfaction and positive affect or the absence thereof (Diener, 2012; Diener and Lucas, 1999). The eudaimonic form defines well-being along a set of dimensions that promote meaning and self-realization (e.g. environmental mastery, personal growth and positive social relations; Ryff, 1989) to advocate fully functioning individuals (Rogers, 1963). Integrating both approaches, the underlying study explores the potential of service to promote the well-being of vulnerable consumers. Depending on the circumstances they are facing, vulnerable consumers may benefit most from services with an emphasis on hedonic (e.g. entertainment) or eudaimonic (e.g. life-coaching) well-being in order for them to overcome the negative consequences of social isolation and thrive in the marketplace. Yet, particularly eudaimonic consumer needs may become significantly more pronounced during periods of crises (Barnes et al., 2020). The next section discusses one particularly promising angle of how service can achieve this goal by deploying social robots.

\section{The transformative potential of social robots}

As a consequence of COVID-19, human service delivery became potentially harmful or in its extremes even lethal to both service providers and consumers (Miriri, 2020). Hence, a particularly promising avenue for service research to support vulnerable consumers during COVID-19 and beyond lies in social robot service. Social robots may increase consumers'
Social robots for consumer well-being

1133 
JOSM 31,6

\section{4}

access to and control over resources and decrease their vulnerability without violating physical distancing or isolation in their pursuit of well-being (Henkel et al., 2017; Hill and Sharma, 2020). Indeed, findings from social robotics in the context of vulnerable consumers report various ways for social robots to promote well-being. For instance, robots that promote social connectedness (e.g. telepresence robots and socially assistive robots) may decrease objective and subjective social isolation for vulnerable consumers including older adults (e.g. Robinson et al., 2014) and children (e.g. Moerman et al., 2019).

Prior research shows that social robots can function as emotional and social actors (Čaić et al., 2019; de Graaf et al., 2015) with a clear transformative mission. They demonstrate social behavior, following the norms of human social interaction (e.g. touch and emotional reactions; Wang and Rau, 2019). With these abilities, social robots create social presence and are perceived as social agents (van Doorn et al., 2017), particularly by children (Kahn et al., 2012) and older adults (Heerink et al., 2009). There is ample evidence in the field of social robotics that vulnerable consumers in social isolation not only promote hedonic (e.g. cheering up) but also eudaimonic well-being. For instance, robots may stimulate environmental mastery and personal growth through advancing communication skills and learning experiences (Baxter et al., 2017; Crompton et al., 2018; Khaksar et al., 2019). They may also help to form positive social relationships, such as assuming roles in socialization, companionship, developing emotional relationships, comforting, coping with stress, anxiety and other negative emotional experiences and supporting ties with other people (Cañamero and Lewis, 2016; Crossman et al., 2018; D'onofrio et al., 2019; Khaksar et al., 2016; Melson et al., 2009).

Robotic transformative potential in times of COVID-19 and beyond - a typology This section synthesizes findings in the social robotics literature that are relevant for the wellbeing of vulnerable consumers facing social isolation. Structuring the status quo and the required future roles of transformative robotic service along three dimensions resulted in four distinct types of robotic transformative service. As depicted in Figure 1, the types are a function of (1) the predominant state of social isolation (i.e. objective vs. subjective), (2) the desired or required well-being emphasis (i.e. hedonic vs. eudaimonic) and (3) robot physical and psychosocial capabilities. As theorized here, the transformative potential of social robots is dependent on future technological advancements, particularly for those consumers who encounter severe subjective social isolation and who require structural support to attain eudaimonic well-being goals. Importantly, the different types resemble the authors'

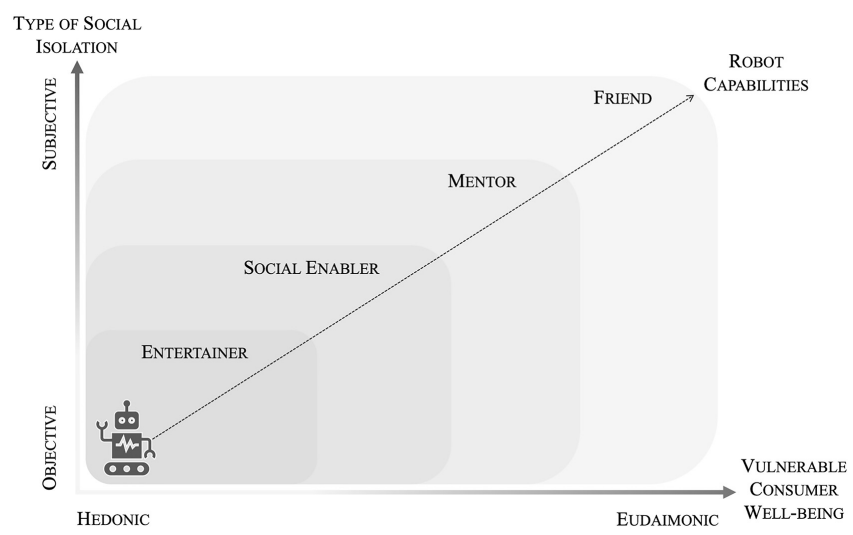

Figure 1.

A typology of robotic transformative service to counter social isolation 
interpretation of respective findings in the literature, and they do not imply a corresponding construal from an emic perspective.

To date, robots with empathetic artificial intelligence (AI) (Huang and Rust, 2018) and human-level physical capabilities (Adalgeirsson and Breazeal, 2010; He et al., 2017) are not yet market ready. However, exactly these types of social robots could provide complex transformative service, based on physical touch, social expressiveness and relationship building (Huang and Rust, 2018). Below, we delineate in detail the transformative potential of each robot type for vulnerable consumers in social isolation, starting with those already being deployed to provide transformative service (i.e. entertainer and social enabler), and concluding with the types that are subject to current (i.e. mentor) and future (i.e. friend) research and development.

\section{Market-ready robotic transformative service roles}

Entertainer. The entertainer robot might be most suitable to serve consumers who face imposed social disconnectedness and, hence, merely experience minor psychological discomfort (e.g. boredom). The entertainer's social capabilities are limited since this robot type is preprogrammed to perform simple and repetitive social tasks. The entertainer may also be less equipped to console consumers through its touch due to its confined physical dexterity and basic embodiment. Its main transformative potential is hedonically oriented and lies in amusing consumers to increase their momentary affect as an end in itself (e.g. enjoyment when playing a game; Leite et al., 2008; dissipation in states of momentary solitude; Odekerken-Schröder et al., in press). It might be deployed to prevent both older adults and children from experiencing minor psychological discomfort during isolation periods (Heljakka and Ihamäki, 2020). An example is Alibaba's DWI Dowellin, a small robot on wheels which entertains users by singing and dancing (Alibaba, 2020).

Social enabler. As a social enabler, the robot may unfold its transformative potential by mediating social interactions for vulnerable consumers. The social enabler robot is not yet imbued with empathetic intelligence; however, with its improved physical capabilities (i.e. physical touch and mirroring social gestures) it can resemble authentic social contact (Rosenthal-von der Pütten et al., 2018). For instance, it can simultaneously display social contacts on screen and simulate their gestures and expressions through its artificial limbs (Adalgeirsson and Breazeal, 2010). During social isolation, this robot type may enable children to continue interacting with their peers and tutors and connect older adults with family, friends, and healthcare service providers from a distance. It might, thus, help socially isolated vulnerable consumers form and maintain positive social relations, and thereby improve academic performance (Furrer and Skinner, 2003) and affective well-being (Schmidt et al., 2019) for children and diminish the negative effects of social isolation on physical (Cornwell and Waite, 2009) and mental (McInnis and White, 2001) health for older adults. Hence, the social enabler bears the potential to transform aspects of both hedonic and eudaimonic consumer well-being. An example is the MeBot, a small robot with two controllable arms and a big display that shows the interaction partner's face (Adalgeirsson and Breazeal, 2010).

\section{Future-oriented robotic transformative service roles}

Mentor. Assuming a mentor role, transformative robotic service is predominantly directed at supporting vulnerable consumers in overcoming threats to their pursuit of eudaimonic wellbeing. During social isolation, both children and older adults are deprived of transformative, self-actualizing services which usually require the presence of a professional service provider (e.g. education, physio- and psycho-therapy). A mentor robot type may autonomously engage consumers on a professional, social and empathetic level while exhibiting nearly human-level physical capabilities (e.g. navigation, touch and object manipulation). With such capabilities,
Social robots for consumer well-being

1135 
JOSM 31,6

mentor robots could embody school teachers and hobby instructors (Niemiec and Ryan, 2009) or physiotherapists (Bhuvaneswari et al., 2013).

Recent findings document that social educational robots can increase consumers' productivity, language skills and physical, cognitive and social-emotional learning experiences (Baxter et al., 2017; Crompton et al., 2018; Khaksar et al., 2019). Likewise, regular physical activity with mentor type robots has been shown to ensure older adults' mobility (Bhuvaneswari et al., 2013; Lopez Recio et al., 2013) prolonging their ability to live independently. Although vulnerable consumers may experience hedonic pleasure during these interactions (Čaić et al., 2019), mentor robots may particularly promote long-term eudaimonic well-being outcomes for children and older adults alike. While such robots are used in research, no fully autonomous version that integrates all mentor-type capabilities exists in the marketplace yet that could substitute a human service provider (Caic et al., 2019). In the future, an example robot for children and older consumers could be physically advanced versions of ICP's Keeko (Low, 2018) or Pal Robotics' GrowMu (Georgiadis et al., 2016), respectively. Both robots combine human-like facial features with verbal communication abilities.

Friend. As a friend, the robot unfolds its transformative potential for vulnerable consumers who experience psychological distress (e.g. loneliness and lack of relatedness) due to both objective and subjective social isolation (Brooks et al., 2020). A friend robot may mitigate these negative consequences through quasi-social interactions. As envisioned here, this type of transformative robotic service would require an empathetic intelligence for rapport building and human-level haptic behaviors (e.g. touching and hugging) to provide solace through physical touch (Tanaka et al., 2007). As a friend, the robot could help alleviate the negative effects of social isolation by providing both hedonic and eudaimonic well-being in the form of genuine care and emotional comfort (Lehoux and Grimard, 2018), personalized service (Robinson et al., 2014; Sorell and Draper, 2014) and rebuilding self-esteem (Leite et al., 2012). Initial evidence suggests that children and older adults may perceive prototypes of such autonomous robots as social beings (Kahn et al., 2012) and friends (Cañamero and Lewis, 2016; Sinoo et al., 2018). While robots assuming a mentor role may predominantly provide eudaimonically oriented professional transformative service, as genuine, loving companions, friend type robots could cater to the entirety of well-being aspects (Crossman et al., 2018; Kachouie et al., 2014). In the future, such a robot might be a significantly advanced version of Pepper, equipped with an empathetic AI.

\section{Discussion and future research agenda}

Vulnerable consumers routinely face adverse circumstances in the marketplace. With the advent of COVID-19, increased social distancing has raised the hurdles to participate in the marketplace for all consumers, and it has exacerbated the social isolation of vulnerable consumers in particular. This study advances a typology of transformative robotic service that integrates work on social isolation (e.g. Hawkley; Cacioppo, 2010), well-being (Ryan and Deci, 2001) and social robotics (e.g. de Graaf et al., 2015) with the aim to cater to the underrepresented group for vulnerable consumers in service research (Rosenbaum et al., 2017).

The typology is derived based on two of the most affected vulnerable consumer groups during COVID-19: children and older adults (Holmes et al., 2020; World Health Organization, 2020a), and its main objective is to guide service researchers, practitioners and consumers on the potential of robotic service to offset the negative consequences of social isolation (Brooks et al., 2020) now and in the future. Figure 2 provides an overview of the conceptual integration of the robot typology into the transformation of hedonic and eudaimonic well-being of vulnerable consumers in the (post) COVID-19 reality. With an increasing level of 


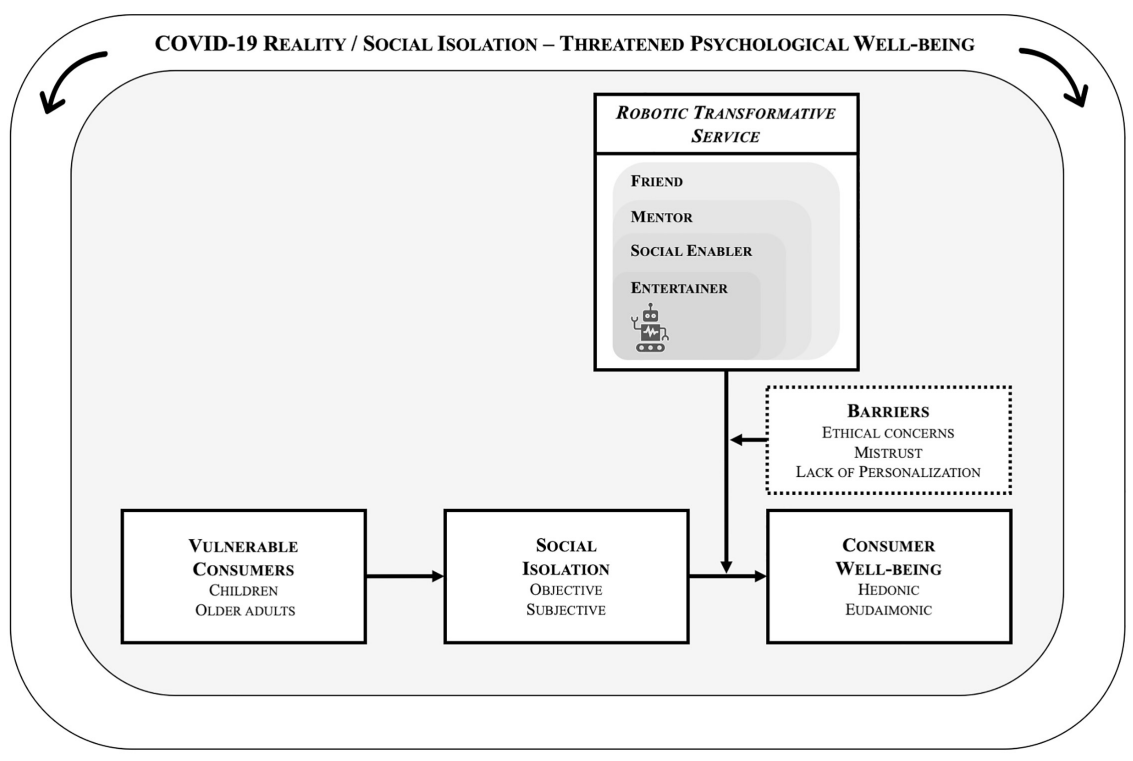

Social robots for consumer well-being

1137

Figure 2. Robotic transformative service infusion during social isolation

sophistication of capabilities, social robots are already equipped to provide transformative service as entertainers and social enablers and in the foreseeable future also as mentors. However, the full spectrum of eudaimonic well-being will likely only be provided by a friendtype robot which does not yet exist in the marketplace. We therefore encourage social robot research and development to focus on designing such a service with the aim to better support vulnerable consumers with a comprehensive focus on eudaimonic well-being.

The theoretical integration of social robot service and well-being suggests a novel, interdisciplinary perspective on the role of service in creating uplifting changes for consumers (Anderson, 2010; Anderson et al., 2013; Anderson and Ostrom, 2015; Gustafsson et al., 2015). Traditionally, a majority of service research has documented predominantly ephemeral, positive (e.g. Oliver et al., 1997) or negative hedonic effects on consumer affect (e.g. Bougie et al., 2003) - mostly as an unintended consequence of service. This study offers an integrative well-being perspective to service and thereby also supplements research on the eudaimonic well-being of consumers (e.g. Guo et al., 2013; Henkel et al., 2017). Through identifying context-dependent (i.e. state of social isolation/well-being emphasis) transformative roles of social robots, the underlying paper identifies a new sub-area for TSR: robotic transformative service research (RTSR).

In accord with the literature review in the field of social robotics on the various roles that transformative robotic service can assume in enhancing the well-being of vulnerable consumers, Table 1 advances an illustrative compilation of future research avenues for RTSR. The agenda is organized along three main topics: (1) the transformative potential of social robots as entertainers, social enablers, mentors and friends, (2) barriers to robotic transformative service potential and (3) eudaimonic consumer well-being. In two additional columns, the table condenses the existing knowledge on each respective topic with exemplary research findings and outlines concrete future research avenues for RTSR. These questions are grouped in themes ranging from robot to service design, over consumer perceptions, ethical considerations and the assessment of robot-facilitated well-being. Rather than providing an exhaustive overview, Table 1 is meant as a catalyst to stimulate research on RTSR. 
JOSM

31,6

1138

Table 1.

Status quo and future research agenda on RTSR in times of COVID-19 and beyond

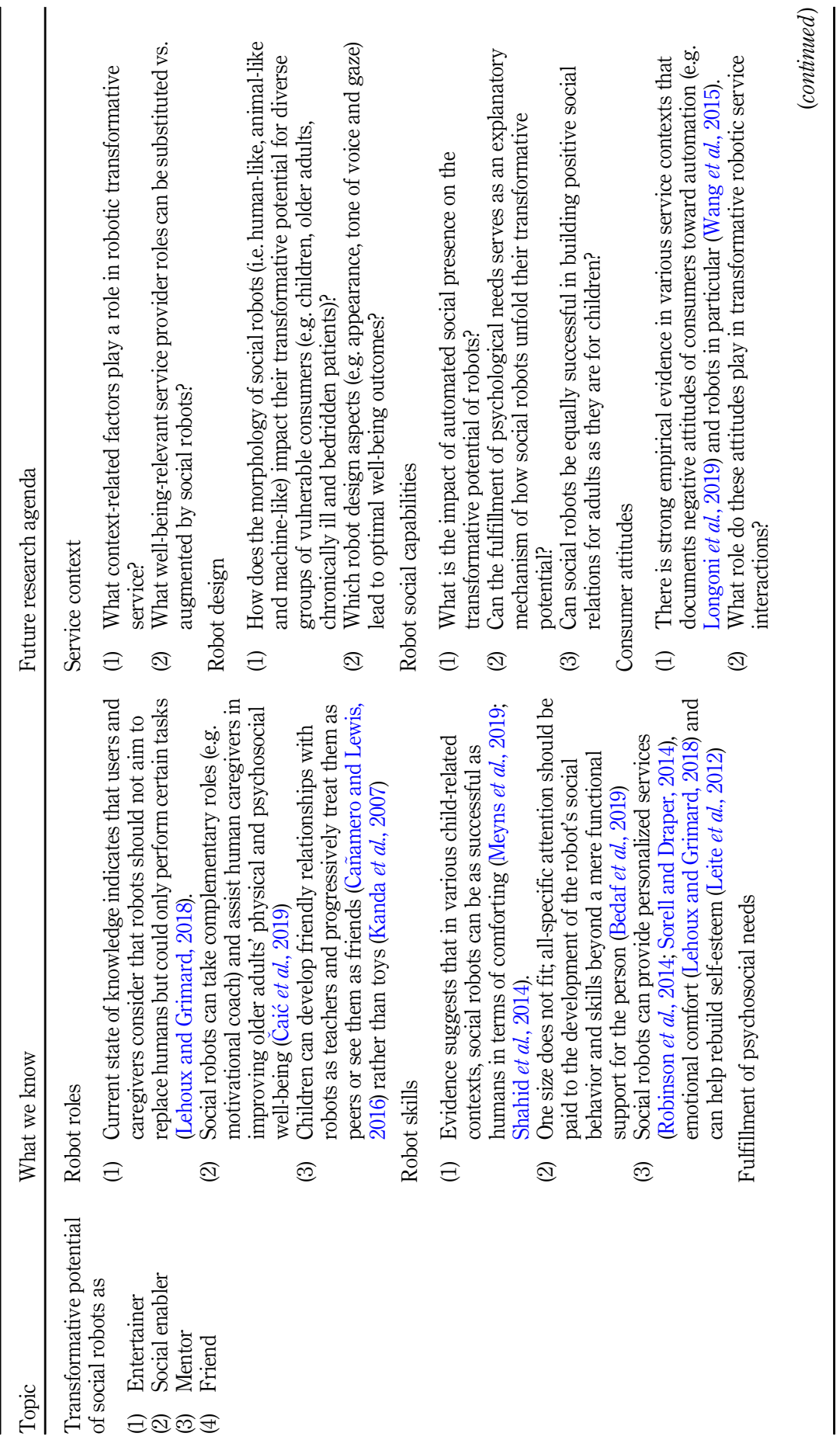




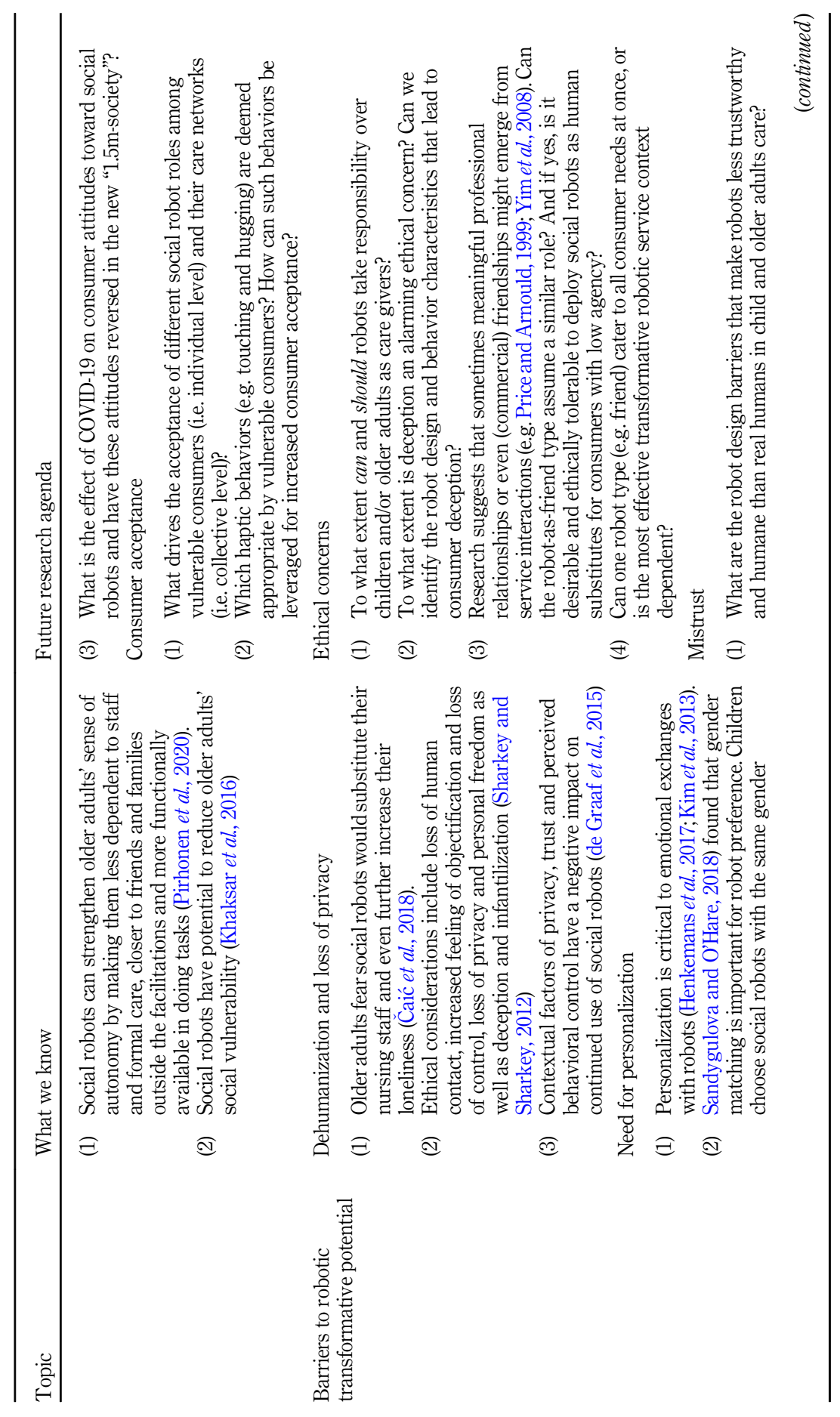

Social robots for consumer well-being

1139

Table 1. 


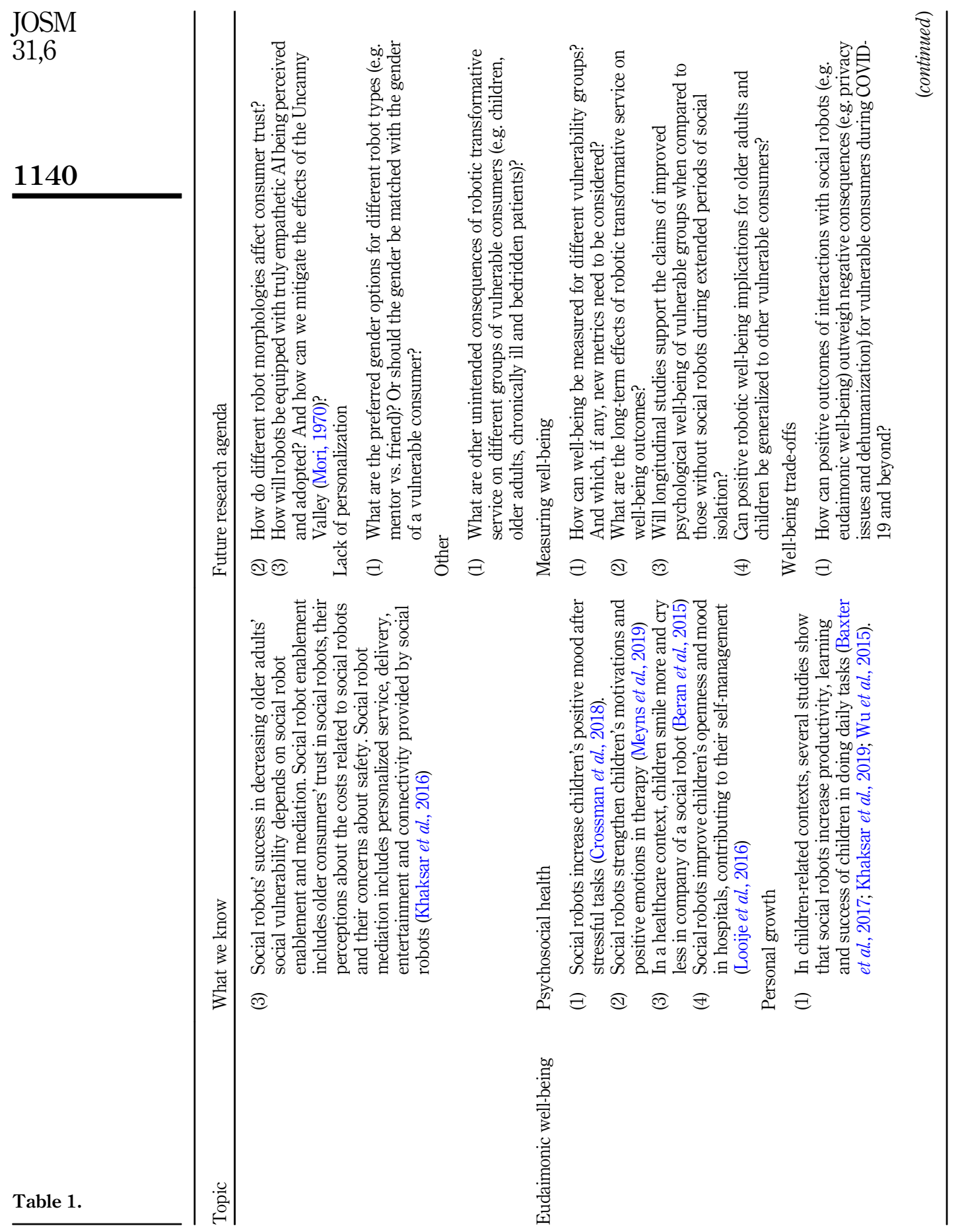




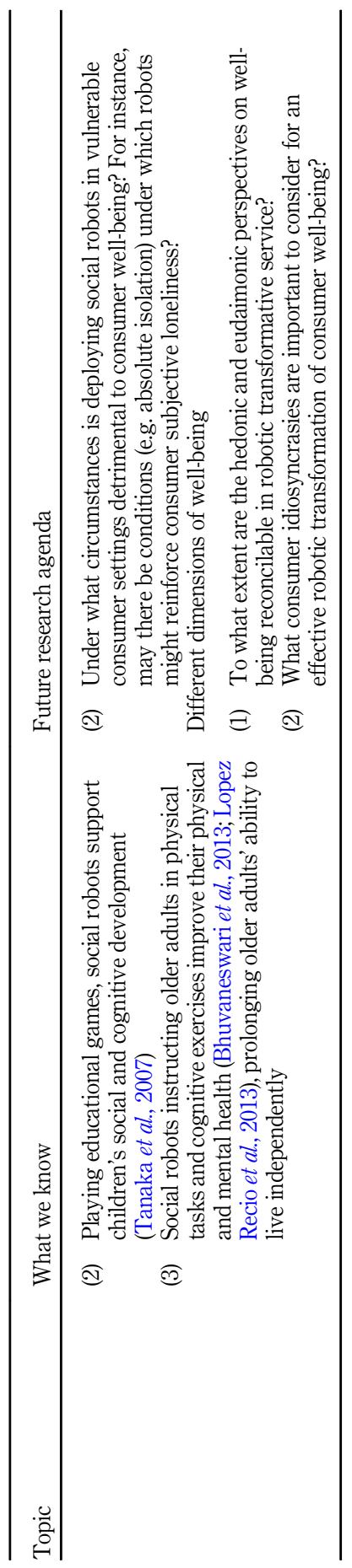

Social robots

for consumer well-being

1141

Table 1. 
JOSM 31,6

The COVID-19 crisis offers a futuristic perspective on the changing role of service. While many services are provided remotely, some are suspended entirely (e.g. Hall et al., in press). For those services that service consumers and providers are still able and required to cocreate physically, social distance is the first priority (cf. Bove and Benoit, in press). It is conceivable that consumers may continue to hold an increased sensitivity toward social interactions with service providers that outlasts COVID-19 (cf. Hazée and van Vaerenbergh, 2020), which may in turn also affect employee well-being (Tuzovic and Kabadayi, in press). Eventually, these developments may surge service innovation (cf. Heinonen and Strandvik, in press). A rapid adoption of automated service may be a consequence. While the underlying paper advances a typology of such robotic service to cater to the well-being of vulnerable consumers facing the abyss of the consequences of social isolation, in the future, transformative robotic service may be considered for creating uplifting changes in well-being for consumers at large.

\section{Note}

1. https://www.softbankrobotics.com/emea/en/pepper

\section{References}

Adalgeirsson, S.O. and Breazeal, C. (2010), "MeBot: a robotic platform for socially embodied telepresence", 2010 5th ACM/IEEE International Conference on Human-Robot Interaction (HRI), presented at the 2010 5th ACM/IEEE International Conference on Human-Robot Interaction (HRI), IEEE, Osaka, Japan, pp. 15-22, doi: 10.1109/HRI.2010.5453272.

Alibaba (2020), "DWI Dowellin Neue Ankunft kleine mini lustige Linie Follower Roboter für Kinder", available at: https://german.alibaba.com/product-detail/dwi-dowellin-new-arrival-small-minifunny-line-follower-robot-for-kids-62054131383.html (accessed 6 May 2020).

Anderson, L. and Ostrom, A.L. (2015), "Transformative service research: advancing our knowledge about service and well-being", Journal of Service Research, Vol. 18 No. 3, pp. 243-249, doi: 10. 1177/1094670515591316.

Anderson, L., Ostrom, A.L., Corus, C., Fisk, R.P., Gallan, A.S., Giraldo, M., Mende, M., Mulder, M., Rayburn, S.W., Rosenbaum, M.S., Shirahada, K. and Williams, J.D. (2013), "Transformative service research: an agenda for the future", Journal of Business Research, Vol. 66 No. 8, pp. 1203-1210, doi: 10.1016/j.jbusres.2012.08.013.

Anderson, L. (2010), "Improving well-being through transformative service", in Ostrom, A.L., Bitner, M.J., Brown, S.W., Burkhard, K.A., Goul, M., Smith-Daniels, V., Demirkan, H. and Rabinovich, E. (Eds), Moving Forward And Making A Difference: Research Priorities For The Science Of Service, Journal of Service Research, Vol. 13 No. 1, pp. 4-36, doi: 10.1177/1094670509357611.

Barnes, D.C., Mesmer-Magnus, J., Scribner, L., Krallman, A. and Guidice, R. (2020), "Customer delight during a crisis: understanding delight through the lens of transformative service research", Journal of Service Management.

Bassuk, S.S., Glass, T.A. and Berkman, L.F. (1999), "Social disengagement and incident cognitive decline in community-dwelling elderly persons", Annals of Internal Medicine, Vol. 131 No. 3, pp. 165-173, doi: 10.7326/0003-4819-131-3-199908030-00002.

Baxter, P., Ashurst, E., Read, R., Kennedy, J. and Belpaeme, T. (2017), "Robot education peers in a situated primary school study: personalisation promotes child learning”, PloS One, Vol. 12 No. 5, p. e0178126, doi: 10.1371/journal.pone.0178126.

Bedaf, S., Marti, P. and De Witte, L. (2019), "What are the preferred characteristics of a service robot for the elderly? a multi-country focus group study with older adults and caregivers", Assistive Technology, Vol. 31 No. 3, pp. 147-157, doi: 10.1080/10400435.2017.1402390.

Beran, T.N., Ramirez-Serrano, A., Vanderkooi, O.G. and Kuhn, S. (2015), "Humanoid robotics in health care: an exploration of children's and parents' emotional reactions", Journal of Health Psychology, Vol. 20 No. 7, pp. 984-989, doi: 10.1177/1359105313504794. 
Bhuvaneswari, P.T.V., Vignesh, S., Papitha, S. and Dharmarajan, R.S. (2013), "Humanoid robot based physiotherapeutic assistive trainer for elderly health care", 2013 International Conference on Recent Trends in Information Technology (ICRTIT), presented at the 2013 Third International Conference on Recent Trends in Information Technology (ICRTIT), Chennai, India, IEEE, pp. 163-168, doi: 10.1109/ICRTIT.2013.6844199.

Bougie, R., Pieters, R. and Zeelenberg, M. (2003), “Angry customers don't come back, they get back: the experience and behavioral implications of anger and dissatisfaction in services", Journal of the Academy of Marketing Science, Vol. 31 No. 4, pp. 377-393, doi: 10.1177/0092070303254412.

Bove, L. and Benoit, S. (in press), "Restrict, clean and protect: signalling consumer safety during the pandemic and beyond", Journal of Service Management.

Brooks, S.K., Webster, R.K., Smith, L.E., Woodland, L., Wessely, S., Greenberg, N. and Rubin, G.J. (2020), "The psychological impact of quarantine and how to reduce it: rapid review of the evidence", The Lancet, Vol. 395 No. 10227, pp. 912-920, doi: 10.1016/S0140-6736(20)30460-8.

Cacioppo, J.T. and Hawkley, L.C. (2009), "Perceived social isolation and cognition", Trends in Cognitive Sciences, Vol. 13 No. 10, pp. 447-454, doi: 10.1016/j.tics.2009.06.005.

Cacioppo, J.T., Hawkley, L.C., Crawford, L.E., Ernst, J.M., Burleson, M.H., Kowalewski, R.B., Malarkey, W.B., William, B., Van Cauter, E. and Berntson, G.G. (2002), "Loneliness and health: potential mechanisms", Psychosomatic Medicine, Vol. 64 No. 3, pp. 407-417, doi: 10.1097/00006842200205000-00005.

Cacioppo, J.T., Hughes, M.E., Waite, L.J., Hawkley, L.C. and Thisted, R.A. (2006), "Loneliness as a specific risk factor for depressive symptoms: cross-sectional and longitudinal analyses", Psychology and Aging, Vol. 21 No. 1, pp. 140-151, doi: 10.1037/0882-7974.21.1.140.

Čaić, M., Odekerken-Schröder, G. and Mahr, D. (2018), "Service robots: value co-creation and codestruction in elderly care networks", Journal of Service Management, Vol. 29 No. 2, pp. 178-205, doi: 10.1108/JOSM-07-2017-0179.

Čaić, M., Avelino, J., Mahr, D., Odekerken-Schröder, G. and Bernardino, A. (2019), "Robotic versus human coaches for active aging: an automated social presence perspective", International Journal of Social Robotics, doi: 10.1007/s12369-018-0507-2.

Cañamero, L. and Lewis, M. (2016), "Making new 'New AI' friends: designing a social robot for diabetic children from an embodied AI perspective", International Journal of Social Robotics, Vol. 8 No. 4, pp. 523-537, doi: 10.1007/s12369-016-0364-9.

Cornwell, E.Y. and Waite, L.J. (2009), "Social disconnectedness, perceived isolation, and health among older adults", Journal of Health and Social Behavior, Vol. 50 No. 1, pp. 31-48, doi: 10.1177/ 002214650905000103.

Crompton, H., Gregory, K. and Burke, D. (2018), "Humanoid robots supporting children's learning in an early childhood setting: humanoid robots supporting children's learning", British Journal of Educational Technology, Vol. 49 No. 5, pp. 911-927, doi: 10.1111/bjet.12654.

Crossman, M.K., Kazdin, A.E. and Kitt, E.R. (2018), "The influence of a socially assistive robot on mood, anxiety, and arousal in children”, Professional Psychology: Research and Practice, Vol. 49 No. 1, pp. 48-56, doi: 10.1037/pro0000177.

D’Onofrio, G., Fiorini, L., Hoshino, H., Matsumori, A., Okabe, Y., Tsukamoto, M., Limosani, R., Vitanza, A., Greco, F., Greco, A., Giuliani, F., Cavallo, F. and Sancarlo, D. (2019), "Assistive robots for socialization in elderly people: results pertaining to the needs of the users", Aging Clinical and Experimental Research, Vol. 31 No. 9, pp. 1313-1329, doi: 10.1007/s40520-018-1073-z.

de Graaf, M.M.A., Allouch, S.B. and Klamer, T. (2015), "Sharing a life with Harvey: exploring the acceptance of and relationship-building with a social robot", Computers in Human Behavior, Vol. 43, pp. 1-14, doi: 10.1016/j.chb.2014.10.030.

Diener, E. and Lucas, R.E. (1999), "Personality and subjective wellbeing", in Kahneman, D., Diener, E. and Schwartz, N. (Eds), Wellbeing: The Foundations of Hedonic Psychology, Russell Sage Foundation, New York, pp. 213-229.
Social robots for consumer well-being 
JOSM 31,6
Diener, E. (2012), "New findings and future directions for subjective well-being research", American Psychologist, Vol. 67 No. 8, pp. 590-597, doi: 10.1037/a0029541.

Fong, T., Nourbakhsh, I. and Dautenhahn, K. (2003), "A survey of socially interactive robots”, Robotics and Autonomous Systems, Vol. 42 Nos 3-4, pp. 143-166, doi: 10.1016/S0921-8890(02)00372-X.

Furrer, C. and Skinner, E. (2003), "Sense of relatedness as a factor in children's academic engagement and performance", Journal of Educational Psychology, Vol. 95 No. 1, pp. 148-162, doi: 10.1037/ 0022-0663.95.1.148.

Georgiadis, D., Christophorou, C., Kleanthous, S., Andreou, P., Santos, L., Christodoulou, E. and Samaras, G. (2016), "A robotic cloud ecosystem for elderly care and ageing well: the GrowMeUp approach", in Kyriacou, E., Christofides, S. and Pattichis, C.S. (Eds), XIV Mediterranean Conference on Medical and Biological Engineering and Computing 2016, Springer International Publishing, Cham, Vol. 57, pp. 919-924, doi: 10.1007/978-3-319-32703-7_179.

Guo, L., Arnould, E.J., Gruen, T.W. and Tang, C. (2013), "Socializing to co-produce: pathways to consumers' financial well-being”, Journal of Service Research, Vol. 16 No. 4, pp. 549-563, doi: 10. 1177/1094670513483904.

Gustafsson, A., Aksoy, L., Brady, M.K., McColl-Kennedy, J.R., Sirianni, N.J., Witell, L. and Wuenderlich, N.V. (2015), "Conducting service research that matters", Journal of Services Marketing, Vol. 29 Nos 6/7, pp. 425-429, doi: 10.1108/JSM-02-2015-0103.

Hall, C.M., Prayag, G., Fieger, P. and Dyason, D. (in press), "Beyond panic buying: consumption displacement and COVID-19", Journal of Service Management.

Hawkley, L.C. and Cacioppo, J.T. (2010), "Loneliness matters: a theoretical and empirical review of consequences and mechanisms", Annals of Behavioral Medicine, Vol. 40 No. 2, pp. 218-227, doi: 10.1007/s12160-010-9210-8.

Hazée, S. and Van Vaerenbergh, Y. (2020), “Customers' contamination concerns: an integrative framework and future prospects for service management", Journal of Service Management.

He, W., Li, Z. and Chen, C.P. (2017), "A survey of human-centered intelligent robots: issues and challenges”, IEEE/CAA Journal of Automatica Sinica, Vol. 4 No. 4, pp. 602-609, doi: 10.1109/JAS. 2017.7510604 .

Heerink, M., Kröse, B., Evers, V. and Wielinga, B. (2009), "Influence of social presence on acceptance of an assistive social robot and screen agent by elderly users", Advanced Robotics, Vol. 23 No. 14, pp. 1909-1923, doi: 10.1163/016918609X12518783330289.

Heinonen, K. and Strandvik, T. (in press), "Reframing service innovation: COVID-19 as catalyst for imposed service innovation", Journal of Service Management.

Heljakka, K. and Ihamäki, P. (2020), in Arai, K., Bhatia, R. and Kapoor, S. (Eds), "Toys that mobilize: past, present and future of phygital playful technology", Proceedings of the Future Technologies Conference (FTC) 2019, Springer International Publishing, Cham, Vol. 1070, pp. 625-640, doi: 10.1007/978-3-030-32523-7_46.

Henkel, A.P., Boegershausen, J., Ciuchita, R. and Odekerken-Schröder, G. (2017), "Storm after the quiet: how marketplace interactions shape consumer resources in collective goal pursuits", Journal of the Association for Consumer Research, Vol. 2 No. 1, pp. 26-47, doi: 10.1086/690463.

Henkemans, O.A.B., Bierman, B.P.B., Janssen, J., Looije, R., Neerincx, M.A., van Dooren, M.M.M., de Vries, J.L.E., van der Burg, G.J. and Huisman, S.D. (2017), "Design and evaluation of a personal robot playing a self-management education game with children with diabetes type 1", International Journal of Human-Computer Studies, Vol. 106, pp. 63-76, doi: 10.1016/j.ijhcs.2017. 06.001.

Hill, R.P. and Sharma, E. (2020), “Consumer vulnerability”, Journal of Consumer Psychology, Vol. 30 No. 3, pp. 551-570, doi: 10.1002/jcpy.1161.

Holmes, E.A., O'Connor, R.C., Perry, V.H., Tracey, I., Wessely, S., Arseneault, L., Ballard, C., Christense, H., Cohen Silver, R., Everall, I., Ford, T., John, A., Kabir, T., King, K., Madan, I., Michie, S., Przybylski, A.K., Shafran, R., Sweeney, A., Worthman, C.M., Yardley, L., Cowan, K., Cope, C., 
Hotopf, M. and Bullmore, E. (2020), "Multidisciplinary research priorities for the COVID-19 pandemic: a call for action for mental health science", The Lancet Psychiatry, Vol. 7 No. 6, pp. 547-560, doi: 10.1016/S2215-0366(20)30168-1.

Holt-Lunstad, J., Smith, T.B., Baker, M., Harris, T. and Stephenson, D. (2015), "Loneliness and social isolation as risk factors for mortality: a meta-analytic review", Perspectives on Psychological Science, Vol. 10 No. 2, pp. 227-237, doi: 10.1177/1745691614568352.

Huang, M.-H. and Rust, R.T. (2018), "Artificial intelligence in service", Journal of Service Research, Vol. 21 No. 2, pp. 155-172, doi: 10.1177/1094670517752459.

Kabadayi, S., Hu, K., Lee, Y., Hanks, L., Walsman, M. and Dobrzykowski, D. (2020), "Fostering older adult care experiences to maximize well-being outcomes: a conceptual framework", Journal of Service Management, doi: 10.1108/JOSM-11-2019-0346.

Kachouie, R., Sedighadeli, S., Khosla, R. and Chu, M.-T. (2014), "Socially assistive robots in elderly care: a mixed-method systematic literature review", International Journal of Human-Computer Interaction, Vol. 30 No. 5, pp. 369-393, doi: 10.1080/10447318.2013.873278.

Kahn, P.H., Kanda, T., Ishiguro, H., Freier, N.G., Severson, R.L., Gill, B.T., Ruckert, J.H. and Shen, S. (2012) "'Robovie, you'll have to go into the closet now': children's social and moral relationships with a humanoid robot”, Developmental Psychology, Vol. 48 No. 2, pp. 303-314, doi: 10.1037/ a0027033.

Kanda, T., Sato, R., Saiwaki, N. and Ishiguro, H. (2007), "A two-month field trial in an elementary school for long-term human-robot interaction”, IEEE Transactions on Robotics, Vol. 23 No. 5, pp. 962-971, doi: 10.1109/TRO.2007.904904.

Khaksar, S.M.S., Khosla, R., Chu, M.T. and Shahmehr, F.S. (2016), "Service innovation using social robot to reduce social vulnerability among older people in residential care facilities", Technological Forecasting and Social Change, Vol. 113 B, pp. 438-453, doi: 10.1016/j.techfore. 2016.07.009.

Khaksar, S.M.S., Khosla, R., Singaraju, S. and Slade, B. (2019), “Carer's perception on social assistive technology acceptance and adoption: moderating effects of perceived risks", Behaviour and Information Technology, doi: 10.1080/0144929X.2019.1690046.

Kim, Y., Kwak, S.S. and Kim, M. (2013), “Am I acceptable to you? effect of a robot's verbal language forms on people's social distance from robots", Computers in Human Behavior, Vol. 29 No. 3, pp. 1091-1101, doi: 10.1016/j.chb.2012.10.001.

Lehoux, P. and Grimard, D. (2018), "When robots care: public deliberations on how technology and humans may support independent living for older adults", Social Science and Medicine, Vol. 211, pp. 330-337, doi: 10.1016/j.socscimed.2018.06.038.

Leite, I., Pereira, A., Martinho, C. and Paiva, A. (2008), “Are emotional robots more fun to play with?”, RO-MAN 2008-The 17th IEEE International Symposium on Robot and Human Interactive Communication, Munich, Germany, IEEE, pp. 77-82, doi: 10.1109/ROMAN.2008.4600646.

Leite, I., Castellano, G., Pereira, A., Martinho, C. and Paiva, A. (2012), "Long-term interactions with empathic robots: evaluating perceived support in children”, in Ge, S.S., Khatib, O., Cabibihan, J.J., Simmons, R. and Williams, M.-A. (Eds), Social Robotics, ICSR 2012, Lecture Notes in Computer Science, Springer Berlin Heidelberg, Berlin, Heidelberg, Vol. 7621, pp. 298-307, doi: 10.1007/978-3642-34103-8_30.

Longoni, C., Bonezzi, A. and Morewedge, C.K. (2019), "Resistance to medical artificial intelligence", Journal of Consumer Research, Vol. 46 No. 4, pp. 629-650, doi: 10.1093/jcr/ucz013.

Looije, R., Neerincx, M.A., Peters, J.K. and Henkemans, O.A.B. (2016), "Integrating robot support functions into varied activities at returning hospital visits: supporting child's self-management of diabetes", International Journal of Social Robotics, Vol. 8 No. 4, pp. 483-497, doi: 10.1007/ s12369-016-0365-8.

Lopez Recio, D., Marquez Segura, L., Marquez Segura, E. and Waern, A. (2013), "The NAO models for the elderly", 2013 8th ACM/IEEE International Conference on Human-Robot Interaction (HRI),
Social robots

for consumer

well-being

1145 
JOSM 31,6

presented at the 2013 8th ACM/IEEE International Conference on Human-Robot Interaction (HRI), Tokyo, Japan, IEEE, pp. 187-188, doi: 10.1109/HRI.2013.6483564.

Low, A. (2018), "China is using adorable robot teachers in kindergartens", cnet, available at: https:// www.cnet.com/news/china-is-using-adorable-robot-teachers-in-kindergartens/ (accessed 5 May 2020).

McInnis, G.J. and White, J.H. (2001), "A phenomenological exploration of loneliness in the older adult", Archives of Psychiatric Nursing, Vol. 15 No. 3, pp. 128-139, doi: 10.1053/apnu.2001.23751.

Melson, G.F., Kahn, P.H., Beck, A., Friedman, B., Roberts, T., Garrett, E. and Gill, B.T. (2009), "Children's behavior toward and understanding of robotic and living dogs", Journal of Applied Developmental Psychology, Vol. 30 No. 2, pp. 92-102, doi: 10.1016/j.appdev.2008.10.011.

Mende, M., Scott, M.L., van Doorn, J., Grewal, D. and Shanks, I. (2019), "Service robots rising: how humanoid robots influence service experiences and elicit compensatory consumer responses", Journal of Marketing Research, Vol. 56 No. 4, pp. 535-556, doi: 10.1177/0022243718822827.

Meyns, P., van der Spank, J., Capiau, H., De Cock, L., Van Steirteghem, E., Van der Looven, R. and Van Waelvelde, H. (2019), "Do a humanoid robot and music increase the motivation to perform physical activity? a quasi-experimental cohort in typical developing children and preliminary findings in hospitalized children in neutropenia”, International Journal of Human-Computer Studies, Vol. 122, pp. 90-102, doi: 10.1016/j.ijhcs.2018.07.010.

Miriri, D. (2020), "Rwandan medical workers deploy robots to minimise coronavirus risk", available at: https://www.weforum.org/agenda/2020/06/rwandan-medical-workers-robots-coronaviruscovid19-risk?fbclid =IwAR1cPR31ubsCXoxufPjtZStf63BpEDfRmGDpswWnvhd87yGAluVtYj0s8M (accessed 6 June 2020).

Moerman, C.J., van der Heide, L. and Heerink, M. (2019), "Social robots to support children's well-being under medical treatment: a systematic state-of-the-art review", Journal of Child Health Care, Vol. 23 No. 4, pp. 596-612, doi: 10.1177/1367493518803031.

Mori, M. (1970), “The uncanny valley”, Energy, Vol. 7 No. 4, pp. 33-35, (in Japanese). A translation that was authorized and reviewed by Mori was published in Mori, M., MacDorman, K.F. and Kageki, N. (2012), "The uncanny valley", IEEE Robotics and Automation Magazine, Vol. 19 No. 2, pp. 98-100, doi: 10.1109/MRA.2012.2192811.

Niemiec, C.P. and Ryan, R.M. (2009), "Autonomy, competence, and relatedness in the classroom: applying self-determination theory to educational practice", Theory and Research in Education, Vol. 7 No. 2, pp. 133-144, doi: 10.1177/1477878509104318.

Odekerken-Schröder, G., Mele, C., Russo Spena, T., Mahr, D. and Ruggiero, A. (in press), "Mitigating loneliness with companion robots in the COVID-19 pandemic and beyond: an integrative framework and research agenda", Journal of Service Management.

Oliver, R., Rust, R.T. and Varki, S. (1997), "Customer delight: foundations, findings, and managerial insight”, Journal of Retailing, Vol. 73 No. 3, pp. 311-336, doi: 10.1016/S0022-4359(97)90021-X.

Pinquart, M. and Sorensen, S. (2001), "Influences on loneliness in older adults: a meta-analysis", Basic and Applied Social Psychology, Vol. 23 No. 4, pp. 245-266, doi: 10.1207/S15324834BASP2304_2.

Pirhonen, J., Melkas, H., Laitinen, A. and Pekkarinen, S. (2020), "Could robots strengthen the sense of autonomy of older people residing in assisted living facilities? - a future-oriented study", Ethics and Information Technology, Vol. 22, pp. 151-162, doi: 10.1007/s10676-019-09524-z.

Price, L.L. and Arnould, E.J. (1999), "Commercial friendships: service provider-client relationships in context”, Journal of Marketing, Vol. 63 No. 4, pp. 38-56, doi: 10.1177/002224299906300405.

Robinson, H., MacDonald, B. and Broadbent, E. (2014), "The role of healthcare robots for older people at home: a review", International Journal of Social Robotics, Vol. 6 No. 4, pp. 575-591, doi: 10. 1007/s12369-014-0242-2.

Rogers, C.R. (1963), "The actualizing tendency in relation to 'motives' and to consciousness", in Nebraska Symposium on Motivation, University of Nebraska Press, Lincoln, NE, Jones, M.R. (Ed.), Vol. 11, pp. 1-24. 
Rosenbaum, M.S., Seger-Guttmann, T. and Giraldo, M. (2017), "Commentary: vulnerable consumers in service settings", Journal of Services Marketing, Vol. 31 Nos 4/5, pp. 309-312, doi: 10.1108/JSM05-2017-0156.

Rosenthal-von der Pütten, A.M., Krämer, N.C. and Herrmann, J. (2018), "The effects of humanlike and robot-specific affective nonverbal behavior on perception, emotion, and behavior", International Journal of Social Robotics, Vol. 10 No. 5, pp. 569-582, doi: 10.1007/s12369-018-0466-7.

Ryan, R.M. and Deci, E.L. (2001), "On happiness and human potentials: a review of research on hedonic and eudaimonic well-being", Annual Review of Psychology, Vol. 52 No. 1, pp. 141-166, doi: 10.1146/annurev.psych.52.1.141.

Ryff, C.D. (1989), "Happiness is everything, or is it? explorations on the meaning of psychological wellbeing", Journal of Personality and Social Psychology, Vol. 57 No. 6, pp. 1069-1081, doi: 10.1037/ 0022-3514.57.6.1069.

Sandygulova, A. and O'Hare, G.M.P. (2018), “Age-and gender-based differences in children's interactions with a gender-matching robot", International Journal of Social Robotics, Vol. 10 No. 5, pp. 687-700, doi: 10.1007/s12369-018-0472-9.

Santini, Z.I., Jose, P.E., York Cornwell, E., Koyanagi, A., Nielsen, L., Hinrichsen, C., Meilstrup, C., Madsen, K.R. and Koushede, V. (2020), "Social disconnectedness, perceived isolation, and symptoms of depression and anxiety among older Americans (NSHAP): a longitudinal mediation analysis", The Lancet Public Health, Vol. 5 No. 1, pp. e62-e70, doi: 10.1016/S24682667(19)30230-0.

Schmidt, A., Dirk, J. and Schmiedek, F. (2019), "The importance of peer relatedness at school for affective well-being in children: between-and within-person associations", Social Development, Vol. 28 No. 4, pp. 873-892, doi: 10.1111/sode.12379.

Shahid, S., Krahmer, E. and Swerts, M. (2014), "Child-robot interaction across cultures: how does playing a game with a social robot compare to playing a game alone or with a friend?", Computers in Human Behavior, Vol. 40, pp. 86-100, doi: 10.1016/j.chb.2014.07.043.

Sharkey, A. and Sharkey, N. (2012), "Granny and the robots: ethical issues in robot care for the elderly", Ethics and Information Technology, Vol. 14 No. 1, pp. 27-40, doi: 10.1007/s10676-0109234-6.

Sinoo, C., van der Pal, S., Blanson Henkemans, O.A., Keizer, A., Bierman, B.P.B., Looije, R. and Neerincx, M.A. (2018), "Friendship with a robot: children's perception of similarity between a robot's physical and virtual embodiment that supports diabetes self-management", Patient Education and Counseling, Vol. 101 No. 7, pp. 1248-1255, doi: 10.1016/j.pec.2018.02.008.

Sorell, T. and Draper, H. (2014), "Robot carers, ethics, and older people", Ethics and Information Technology, Vol. 16 No. 3, pp. 183-195, doi: 10.1007/s10676-014-9344-7.

Steptoe, A., Shankar, A., Demakakos, P. and Wardle, J. (2013), "Social isolation, loneliness, and allcause mortality in older men and women", Proceedings of the National Academy of Sciences, Vol. 110 No. 15, pp. 5797-5801, doi: 10.1073/pnas.1219686110.

Tanaka, F., Cicourel, A. and Movellan, J.R. (2007), "Socialization between toddlers and robots at an early childhood education center", Proceedings of the National Academy of Sciences, Vol. 104 No. 46, pp. 17954-17958, doi: 10.1073/pnas.0707769104.

Tuzovic, S. and Kabadayi, S. (in press), "The influence of social distancing on employee wellbeing: a conceptual framework and research agenda", Journal of Service Management.

van Doorn, J., Mende, M., Noble, S.M., Hulland, J., Ostrom, A.L., Grewal, D. and Petersen, J.A. (2017), "Domo arigato Mr. Roboto: emergence of automated social presence in organizational frontlines and customers' service experiences", Journal of Service Research, Vol. 20 No. 1, pp. 43-58, doi: 10. 1177/1094670516679272.

Wang, B. and Rau, P.-L.P. (2019), "Influence of embodiment and substrate of social robots on users' decision-making and attitude", International Journal of Social Robotics, Vol. 11 No. 3, pp. 411-421, doi: 10.1007/s12369-018-0510-7.
Social robots

for consumer well-being 
JOSM 31,6

Wang, S., Lilienfeld, S.O. and Rochat, P. (2015), "The uncanny valley: existence and explanations", Review of General Psychology, Vol. 19 No. 4, pp. 393-407, doi: 10.1037/gpr0000056.

Wirtz, J., Patterson, P.G., Kunz, W.H., Gruber, T., Lu, V.N., Paluch, S. and Martins, A. (2018), "Brave new world: service robots in the frontline", Journal of Service Management, Vol. 29 No. 5, pp. 907-931, doi: 10.1108/JOSM-04-2018-0119.

World Health Organization (2020a), "Coronavirus disease 2019 (COVID-19) situation report - 51", available at: https://www.who.int/docs/default-source/coronaviruse/situation-reports/20200311sitrep-51-COVID-19.pdf?sfvrsn=1ba62e57_10 (accessed 06 May 2020).

World Health Organization (2020b), "Mental health and psychological resilience during the COVID-19 pandemic", available at: http:/www.euro.who.int/en/health-topics/health-emergencies/ coronavirus-COVID-19/news/news/2020/3/mental-health-and-psychological-resilience-duringthe-COVID-19-pandemic (accessed 10 June 2020).

Wu, W.-C.V., Wang, R.-J. and Chen, N.-S. (2015), "Instructional design using an in-house built teaching assistant robot to enhance elementary school English-as-a-foreign-language learning", Interactive Learning Environments, Vol. 23 No. 6, pp. 696-714, doi: 10.1080/10494820.2013. 792844.

Yim, C.K.(Bennett), Tse, D.K. and Chan, K.W. (2008), "Strengthening customer loyalty through intimacy and passion: roles of customer-firm affection and customer-staff relationships in services”, Journal of Marketing Research, Vol. 45 No. 6, pp. 741-756, doi: 10.1509/jmkr.45.6.741.

\begin{abstract}
About the authors
Alexander P. Henkel is an Assistant Professor at the Faculty of Management at the Open University of the Netherlands. He is also affiliated with the Center for Actionable Research of the Open University (CAROU) at the Brightlands Smart Services Campus in Heerlen, the Netherlands. Alexander P. Henkel is the corresponding author and can be contacted at: alexander.henkel@ou.nl

Martina Caić is a post-doctoral researcher at CTF-Service Research Center at Karlstad University in Sweden and Aalto University, School of Arts, Design and Architecture in Finland. She is also an associate researcher at Hanken School of Economics in Finland. Her research addresses customer experiences in value networks, with a particular focus on robotic and ambient assisted living technologies.

Marah Blaurock is a research assistant and doctoral candidate at the chair of corporate management at the University of Hohenheim in Germany. Her $\mathrm{PhD}$ project is focused on human perceptions of artificial intelligence and robots in service interactions.

Mehmet Okan is an Assistant Professor at the Faculty of Management at the Artvin Çoruh University in Turkey. His research addresses employee-customer relationships, dysfunctional behaviors of service actors and meta-analysis and other systematic literature reviews.
\end{abstract}

For instructions on how to order reprints of this article, please visit our website:

www.emeraldgrouppublishing.com/licensing/reprints.htm

Or contact us for further details: permissions@emeraldinsight.com 